rev.relac.int.estrateg.segur.7(1):149-172,2012

\title{
EXCESOS Y CRIMINALIDAD EN LA ÉLITE DE PODER*
}

\author{
Asael Mercado Maldonado**
}

\section{RESUMEN}

El objetivo de este artículo es analizar como en la élite del poder se generan dos fenómenos determinantes: la opulencia exacerbada que provoca excesos y excentricidades y el modus operandi del criminal de cuello blanco. Describo los excesos y excentricidades de la élite de poder internacional más famosa del mundo. Y caracterizo el modus operandi del criminal de cuello blanco como una figura de reconocimiento internacional que tiene varios rostros y distintos objetivos, pero el fin es el mismo: usar la organización criminal para desarrollar sus acciones.

Palabras clave: criminales de cuello blanco, empresas, fraude, excentricidades, concentración de riqueza.

* Este artículo es producto derivado de la investigación titulada: Élite de poder y pobreza en un mundo globalizado. Clave 2505, Financiada por la Universidad Autónoma del Estado de México; el reporte final fue aprobado el 15 de Enero del 2011. El responsable es Dr. Asael Mercado Maldonado y colaboradores el Dr. Ranulfo Pérez Garcés y el Dr. Nicolás Gallegos Magdaleno.

** Doctor en ciencias políticas y sociales. Profesor investigador de tiempo completo de la Facultad. de Ciencias Políticas y Sociales de la Universidad Autónoma del Estado de México. Líder del cuerpo académico: Nuevo orden mundial; Retos políticos y económicos para el siglo XXI, UAEM-2011. asaellmm@hotmail.com 


\title{
EXCESSES AND DELINQUENCY IN THE ELITE OF POWER
}

\begin{abstract}
The object of this article is to analyze how in the elite of power two decisive phenomena are created: the extreme affluence that causes excesses and eccentricities, and the modus operandi of white-collar criminals. The excesses and eccentricities of the world's most famous international power elite are described and the modus operandi of the white-collar criminal is characterized as a figure of international notoriety, with varied facades and assorted objectives, but the end is the same: to use the criminal organization to carry out his actions.
\end{abstract}

Key words: white-collar criminals, businesses, fraud, eccentricities, concentration of wealth.

\section{EXCESSO E CRIMINALIDADE NA ELITE DO PODER}

\section{RESUMO}

O objetivo deste artigo e analisar como se formam na elite do poder dois fenômenos determinantes: a opulência exorbitante que provoca excesso e excentricidades e o modus operandi do criminoso de colarinho branco. Descrevo os excessos e excentricidades da elite do poder internacional mais famosa do mundo. Também caracterizo o modus operandi do criminoso de colarinho branco como uma figura de reconhecimento internacional que tem várias faces e diferentes objetivos, mas com a mesma finalidade: usar a organização criminosa para desenvolver seus atos.

Palavras chave: criminosos de colarinho branco, empresas, fraude, excentricidades, concentração da riqueza. 


\section{INTRODUCCIÓN}

El objetivo general de la investigación es generar una aproximación teórico-empírica sobre las élites de poder, a fin de conocer y/o identificar la significancia que estas tienen en la configuración de los nuevos escenarios de convivencia social, en donde la pobreza aparece como un fenómeno agudizado, en el mundo actual globalizado.

La investigación global abarca varios apartados: definimos a la globalización como un escenario de lucha de clases o redes sociales que implica un orden societario fundado y promovido por ciertas élites de diversos países que se ven beneficiadas del proceso de globalización. Los beneficios mayores siempre serán para las empresas con mayor poder económico y político a nivel internacional, generalmente ubicadas en los Estados desarrollados. Analizamos el concepto de élite rescatando las aportaciones de los autores clásicos que explican sus orígenes y protagonistas principales. El espacio estadounidense y su liderazgo en el mundo occidental, con la aparición de una nueva élite de poder conocida como Los amos del universo que están definiendo el nuevo orden mundial de acuerdo con sus intereses. La existencia de esa nueva élite proviene fundamentalmente de las siguientes fuentes originales: 1) Hermandades y Sectas 2) Líderes corporativos 3) Estrategas intelectuales y militares. La preeminencia de esa élite occidental ha generado las principales guerras del siglo XXI por los últimos recursos planetarios desde 1992 hasta 2010, en Medio Oriente, Libia y ahora África. Se destaca la importancia de la élite de poder en América Latina describiendo en un cuadro analítico el perfil social y las propiedades de los principales magnates latinos conocidos como los amos de América Latina y, particularmente, la élite en México con su poderosa organización: El Consejo Mexicano de Hombres de Negocios. Por último, describimos los excesos y excentricidades de los principales hombres más ricos del mundo destacando el costumbrismo de los temidos criminales de cuello blanco y los retos del sistema penal para vigilar y castigar los delitos cometidos en sus ámbitos de acción. De esta última parte se deriva el presente artículo.

La primera vez que se presentó el concepto de delito de cuello blanco fue en la Reunión Anual de Diciembre de 1939 de la American Sociological Society con sede en Filadelfia, presentado por Edwin H. Sutherland, definido como aquel ilícito penal cometido por sujetos de elevada condición social en el curso o en relación con su actividad profesional. Este objeto de estudio proviene de la vertiente académica de la Escuela de Chicago ${ }^{1}$ sobre la interacción en las ciudades y su complejo sistema penal aplicado de manera diferencial y selectiva entre las distintas capas sociales.

1. Los fundadores de la Escuela de Chicago, incluyendo a Albion Small, W. I. Thomas, Znaniecki, George Herbert Mead, Ernest Burgess, Robert Ezra Park y LouisWirth, crearon y mantuvieron un esquema pleno del pensamiento sociológico, bajo la guía de Thomas y Mead, cuyas teorías cimentaron el marco de la investigación de las ciencias sociales actualmente. 
Los criminales de cuello blanco poseen condiciones socioeconómicas elevadas, violan las leyes diseñadas para regular su ocupación profesional y se desenvuelven en grupos sociales superiores a los de la mayoría de la población. No siempre ejercen actos delictivos con metas económicas, muchas veces desean lograr reconocimiento social o por la búsqueda de mayor poder.

El criminólogo alemán Werner Ruther de la Universidad de Colonia, al referirse a la falta de tipificación de ciertos delitos financieros y a las personas que intervienen en las nuevas modalidades delincuencia afirma que:

Se debe modificar la imagen de la criminalidad -hasta ahora considerada solamente en relación con la pertenencia a bajos estratos sociales y familias desordenadas- y asociar la criminalidad también a estratos sociales elevados, poniendo en práctica el establecimiento de nuevas normas y como en el caso de los delitos económicos graves, deben ser tipificados en la ley penal y perseguirlos por medio de los fiscales. (Zambrano, 2011:10)

El contexto social se caracterizaba por una creciente urbanización, desorganización social, racismo y concentración industrial; así mismo, trajo los llamados negocios ilegales como la ley seca y la propia corrupción administrativa; los criminólogos se enfocaron también al estudio del crimen organizado.

En el artículo desarrollo las características del criminal de cuello blanco, su modus operandi, la composición del crimen organizado en Norteamérica, los excesos y excentricidades de los más ricos y su vida en la nueva ciudad de ensueño, Dubái.

\section{1. ÉLITE DE PODER: EL CRIMINAL DE CUELLO BLANCO}

El criminal de cuello blanco "es desalmado, planifica sus crímenes en una mesa ejecutiva, en una junta directiva, tiene la capacidad, la inteligencia y la frialdad para desarrollar múltiples estrategias y conseguir sus objetivos al precio que sea, y no duda ni un instante en usar su poder e influencia, para eliminar a sus enemigos". "Usa la intimidación, el chantaje, la extorsión y el soborno, para lograr sus fines. Este tipo de criminal es un individuo que maneja los hilos del poder, compra votos para favorecer partidos, compra políticos para cambiar leyes, soborna funcionarios para obtener contratos". (Lugo, 2005: 5).

Los criminales de cuello blanco poseen una carga de conocimiento técnico, teórico, científico y tecnológico que les permite consolidar el control de sus propios intereses. Las estructuras que asumen los criminales de cuello blanco son las organizaciones criminales llamadas empresas criminales donde hacen negocios de manera nociva y perjudicial. La violación de leyes inmersas en el mercado, evasión de impuestos, fraudes millonarios y todo bajo la máscara del servicio y atención al público. Otro tipo de empresas son las llamadas empresas fachada; que se dedican 
al "lavado de dinero y activos" provenientes del crimen organizado sea de corte nacional o internacional como el contrabando y el narcotráfico.

El perfil psicológico de estos criminales cambia notablemente; su fama era pública, ostentaban y disfrutaban de la publicidad. Actualmente, es difícil identificar a un criminal de cuello blanco; hay que descifrar su Modus Operandi, su personalidad, la dimensión de su entorno e impacto de sus actividades; precisar el tipo de crimen que predomina en su actividad delictiva; la temeridad y riesgo con que realiza sus operaciones, la frialdad de sus actos, su círculo social y la edad.

El criminal de cuello blanco posee "educación superior, muy ambicioso, y no escatima esfuerzos para ser un líder en su área; se ocupa personalmente de cada detalle y delega funciones con cuidado para que no se cometan errores; es perfeccionista, minucioso, gusta de afrontar situaciones críticas y maneja un bajo perfil para no despertar sospecha" (Lugo, 2005: 20).

El criminal de cuello blanco es una figura de reconocimiento internacional, tiene varios rostros y distintos objetivos, pero el fin es el mismo: el lucro. Depende de la organización criminal para el desempeño de sus acciones, pero estas organizaciones no son nuevas, tienen una trayectoria histórica tanto en la economía como en la vida política del país. Estas organizaciones vinculadas con políticas de Estado promueven grandes empresas capitalistas que se dedican a la especulación, el reciclaje de dinero, contrabando de drogas y al uso clientelar de partidos políticos para sus fines dentro de la administración y gestión pública.

Según la Teoría de la Personalidad las características que presenta la estructura psíquica del delincuente de cuello blanco son:

- Materialista: sólo da valor a los bienes materiales. Es un auténtico maniaco, su tensión patológica se libera con la ganancia siendo su Psicología similar a la de un jugador.

- Egocentrismo: no alcanza a lograr afectividad; esta soledad la compensan mostrándose caritativos y generosos.

- Narcisismo: los hace soberbios, insensibles y se traduce a su situación social, ropas, dinamismo, inteligencia y audacia.

- Peligrosidad: no valoran límites éticos.

- Hipocresía: son fríos y se muestran generosos.

- Neuróticos: falta de conciencia de culpabilidad, se debe a que estos actos no provocan reacción. (Corigliano, 2005: 7) 
La clase de los hombres que integran la élite del poder se adhieren decididamente al fin social dominante del éxito económico y harán hasta lo imposible por conseguirlo y mantener su status de privilegio. En su obsesión por mantener sus privilegios esta minoría social puede cometer delitos de cuello blanco. Sin embrago, por la debilidad institucional y la impunidad, los magnates y gobernantes son escasamente perseguidos.

En un estudio que cubre todos los dictadores en 199 países que gobernaron entre los años 1946 y 2000, el resultado más común, tras el derrocamiento o la abdicación de un dictador, es que permanece en el país, al menos a corto plazo, sin recibir castigo alguno. Atendiendo a la muestra global de dictadores, 31\% (170) de ellos permanecieron impunes en sus países. En América Latina, los dirigentes salientes impusieron la aprobación de leyes de impunidad como condición a una transición pacífica hacia la democracia, evitando así posibles enjuiciamientos por sus excesos pasados. El segundo resultado más común ha sido el exilio: cerca de 18\% (97) de los dictadores fueron capaces de huir de sus países y encontrar refugio en otros autoritarios o incluso en democracias amigas. Por ejemplo, Idi Amín huyó de Uganda a Libia en 1979. Jean Claude Duvalier, ex presidente de Haití, ha vivido exiliado en Francia desde 1986. Alfredo Stroessner de Paraguay se refugió en Brasil. Para los líderes africanos fue creado por el gobierno americano el puesto de African president in Residence en la Universidad de Boston, donde viven cómodamente con su propio cuerpo de seguridad y servicio. Como el ex dictador de Zambia, Kenneth Kaunda y Ruth Perry de Liberia.

Tan solo unos cuantos (89) fueron asesinados o encarcelados por aquellos que tomaron el poder. Destacan los casos de Nicolás Ceaucescu en Rumania y Sukarno en Indonesia. Solo 52 dictadores $(9.58 \%)$ fueron capaces no solamente de permanecer impunes, sino que además se aseguraron un cargo prominente en las nuevas instituciones o permanecieron en las antiguas. Como ejemplo está Augusto Pinochet, quien intercambió su cargo como comandante en jefe de las fuerzas armadas por un puesto vitalicio en el senado chileno. En el año 2000 había 70 líderes autoritarios en el poder. (Escribá, 2008: 427-428-429)

A continuación describiré las tendencias principales de la financiación de las guerras. Los grupos rebeldes dependen principalmente de las siguientes actividades económicas:

- El control y la explotación ilegales de los recursos naturales legales, los cuales son comercializados en mercados locales e internacionales.

- El cobro ilegal de impuestos y el control de mercados ilegales con altos márgenes de ganancia, tal como el de la cocaína. la heroína y el cannabis.

- El control local y regional de la economía subterránea por medio de la producción y el tráfico ilegal de bienes de consumo o de servicios legales. Robo, extorsión y secuestro. 
- La movilización de las diásporas para obtener donaciones voluntarias o para explotarlas por medio de la extorsión.

Las fuerzas de seguridad del Estado dependen principalmente de:

- $\quad$ Regalías de recursos naturales e inversión extranjera.

- Impuestos.

- $\quad$ Asistencia externa de otros países.

Collier y Hoeffler concluyeron que los países cuyas exportaciones estuvieran compuestas en $32 \%$ por productos primarios estarían en mayor riesgo de conflicto. En los países altamente combatientes existen ladrones armados y organizados movidos por el deseo de enriquecerse. Parafraseando a Carl Von Clausewitz, David Keen se refirió a la guerra como "la continuación de fines económicos por otros medios" y argumentó que las guerras en lugar de ser episodios de caos, tienen funciones económicas racionales de orden individual, como el lucro.

Paul Collier y Anke Hoeftler, basado en un estudio econométrico de al menos 60 episodios de guerras civiles, argumentaron que las guerras civiles estaban más relacionadas con rebeldes y mercenarios avaros que con protestas contra del autoritarismo y la pobreza. Collier llevaba décadas trabajando en temas de desarrollo económico y estaba convencido de que uno de los impedimentos más grandes del continente Africano para salir adelante en términos socio-económicos era individuos explotadores y gobernantes corruptos que se valían de cuasi-ejércitos para engordar sus cuentas en paraísos fiscales, como el caso de Charles Taylor, el presidente de Liberia de Ionas Savimbi, el líder de UNITA en Angola: o de Foday Sankoh el líder del Frente Revolucionario Unido en Sierra Leona.

Collier y Hoeffler recibieron muchas críticas que los obligaron a retirar su estudio y, sobre todo, a cambiar el lenguaje de sus interpretaciones. Sin embargo, el estudio puso sobre la mesa un punto fundamental sobre las guerras civiles que nadie podía negar. Para que una rebelión fuera exitosa 0 para que una guerra durara se necesitaban recursos económicos. (Guáqueta, 2003: 92-96-97)

Es importante reconocer el poder corruptor de las organizaciones que tienen como fines la acumulación de ganancias ilícitas. El fenómeno de contaminación de las relaciones económicas ilícitas por parte de la criminalidad organizada va de la mano con la globalización de las relaciones económicas y de las libertades que brindan las redes del comercio internacional. La similitud estructural entre una organización criminal y la empresa como agente económico otorga cierta funcionalidad para moverse fácilmente por el mundo social y económico. Las organizaciones criminales adoptan como punto de referencia los modelos y estructuras del mundo de la industria y los negocios. 
En la actualidad, se consolida una industria del crimen presente en varios países con mafias que lograron infiltrarse en las relaciones sociales y políticas. Contaminando empresas legales para mezclar el capital ilícitamente obtenido en el capital "sano" de empresas privadas. Aparecen necesidades mutuas dentro del ciclo productivo: encubrimiento de delitos, lavado de dinero y financiación para la comisión de delitos, empresas fantasmas para financiar las organizaciones criminales. Muchos comportamientos en el ámbito de las empresas se desarrollan entre los límites de la legalidad y la ilegalidad, por ejemplo, el fraude de subvenciones, abuso de información privilegiada, una autorización con tráfico de influencias.

Criminalidad organizada y criminalidad del poder se materializó en la estructura creada por la asociación Montesinos-Fujimori, la cual se infiltró en las redes económicas y sociales del Perú, socavando las instituciones democráticas con el fin de hacerlas afines a sus designios económico-políticos. En México el caso de Jorge Hank Rohn, alcalde de la cd. fronteriza de Tijuana del 2004 al 2006 donde opera el Hipódromo de Agua Caliente y casinos instalados en 19 estados, ha sido vinculado a homicidios, posesión de armas y contrabando; de todos los cargos ha quedado en libertad. En 2006 en una entrevista con Fidel Samaniego a la pregunta: ¿Cuál es tu animal favorito? respondió: "La mujer es mi animal favorito". (El Universal, 6/VI/2011). Tiene por costumbre tomar un brebaje afrodisiaco que contiene pene de León, de Tigre y perro, así como cuerno de venado, hiel Oso, 8 víboras de cascabel y alacranes. (CNN 18/VIII/2011). Se le vincula políticamente con el grupo de poder Atlacomulco al que perteneció su padre el maestro Carlos Hank González, prominente político mexicano que fue gobernador del Estado de México y regente de la cd. de México.

La criminalidad no es exclusiva del ámbito político o financiero, también se encuentra en espacios eclesiásticos o artísticos. Marcial Maciel, fundador de los Legionarios de Cristo, abusó sexualmente de sus hijos mexicanos, quienes lo denunciaron al revelar que la alta jerarquía de la legión conocía de sus prácticas. Además, se dio a conocer que Maciel recibía donativos de empresarios que no ingresaba a las arcas de la congregación.

En entrevista con la periodista Carmen Aristegui, los hijos de Marcial Maciel, José Raúl, Christian y Omar González Lara, así como quien fuera su pareja por 25 años, Blanca Estela Lara Gutiérrez, narraron, por primera vez públicamente, parte de la doble vida del fundador de la congregación religiosa más poderosa de la Iglesia católica en las últimas décadas.

Detalló durante la entrevista radiofónica su primer hijo con Blanca Estela, José Raúl dijo: "Mi primer abuso sucedió cuando tenía siete años de edad en Colombia; yo estaba acostado con él, me baja mi calzoncillo y me intenta violar. Por instinto humano reacciono y me muevo. Se da cuenta, no me fuerza. De ahí empezaron todos los abusos; hubo abusos muy fuertes; hubo abusos sexuales en Madrid; hacía que lo masturbáramos, que le sacáramos fotos masturbándolo". (Jiménez, 2010:1) 
Mientras a su hermano Omar lo había enviado a Denver, éste también dijo haber sido víctima de abusos sexuales: "mi primer abuso fue cuando fuimos a Madrid, en ese entonces le dije a Raúl: sabes qué, vamos a masturbarlo. Y niños pequeños con malicia, estábamos juntos, en ese entonces me acuerdo que se hacía el dormido y empezamos a masturbarlo, siempre nos decía que a él le dolían mucho las piernas que durmiéramos alguno de los dos siempre con él, con el afán de que nos decía "tengo un dolor en los huesos, caliéntame la pierna porque me duele mucho". (Jiménez, 2010:1)

Marcial Maciel murió el 31 de enero del 2008 en Cotija Michoacán, México a los 87 años de edad. Se documentaron 94 acusaciones por abusos sexuales contra menores. Siempre recibió la protección del Juan Pablo II y de Joseph Ratzinger, hoy Papa Benedictino XVI.

Otro caso famoso por sus repercusiones a nivel internacional en el ámbito de los medios es el escándalo en el emporio periodístico de Rupert Murdoch. Stuart Kuttner, el ex director gerente del dominical 'News Of The World' es sospechoso de corrupción por pagos indebidos a agentes policiales y de interceptación de comunicaciones. Son once los detenidos en el Reino Unido por el caso de las escuchas, en su mayoría periodistas del dominical 'News of the World', clausurado el pasado 10 de julio 2011.

Entre los detenidos, que se encuentran en libertad bajo fianza, se incluyen la ex directora del periódico Rebekah Brooks, mano derecha de Murdoch en el Reino Unido, y el ex director Andy Coulson, hasta enero jefe de prensa del primer ministro, David Cameron. Además, dos comisarios jefe de Scotland Yard, Paul Stephenson y John Yates, han dimitido por sus conexiones con los implicados en el caso. Donde existió complicidad de espionaje contra miembros de la familia real. La investigación policial sobre las escuchas abarca dos aspectos, el espionaje telefónico para obtener exclusivas -enmarcado en la operación Weeting- y los sobornos a la Policía, objetivo de la operación Elveden.

El escándalo de las escuchas, que estalló en 2006, se agravó el mes pasado al conocerse que además de teléfonos de famosos habían espiado los de familiares de soldados muertos y víctimas de asesinatos célebres.

Rupert Murdoch pidió disculpas al mundo por su comportamiento sin escrúpulos. Al final, la corte de Magistrados de Westminster sentenció a seis semanas de cárcel al humorista que arrojó espuma de afeitar al magnate, cuando éste compareció ante el Parlamento británico el 20 de julio del 2011 y Murdoch permanece libre.

Quizás el caso más conflictivo que enfrentó de Derecho internacional fue el del dictador Augusto Pinochet detenido en Londres, Inglaterra, por su responsabilidad en la ejecución de por los menos más 100 españoles asesinados en las mazmorras de su dictadura que comenzó en 1973. 
La sala de magistrados voto por mayoría dividida para que regresara a Chile evitando su arresto y deportación para ser procesado por autoridades españolas.

El Proyecto de Convención de Naciones Unidas contra la criminalidad transnacional organizada, de marzo de 1999, obligaría a los Estados que ratifiquen la Convención a la tipificación penal de las conductas de "participación en una organización criminal". Se considera grupo criminal organizado a un grupo estructurado de tres personas o más existente desde hace un cierto tiempo y que tiene por fin la comisión de infracciones graves para obtener, directa o indirectamente, un beneficio financiero o material de otro tipo.

El XVI Congreso Internacional de Derecho Penal, celebrado en Budapest. En septiembre de 1999 se ocupó de "Los sistemas de justicia penal ante el desafío del crimen organizado". En este evento se llegó a definir las características del crimen organizado:

- La división del trabajo y la disolución de la responsabilidad individual en el seno de la organización.

- $\quad$ La intercambiabilidad de los individuos.

- $\quad$ El secreto.

- La mezcla de actividades legitimas e ilegitimas.

- La capacidad de neutralizar los esfuerzos de aplicación de la ley mediante la intimidación o corrupción.

- La capacidad especial de transferencia de las ganancias.

El congreso definió el crimen organizado como un tipo de delincuencia que persigue la obtención de poder y/o lucro a través de una organización fuertemente estructurada. El crimen organizado plantea nuevos retos para el Derecho Penal hacerle frente; destaca la incriminación de la pertenencia a una organización criminal, entendiendo la "pertenencia" como la creación, dirección, financiación o adhesión a la asociación.

La impunidad creciente en nuestras sociedades permite que prácticamente todos los delitos realizados dentro de aparatos organizados, llámese bandas criminales, organizaciones empresariales, organismos del Estado, organismos paramilitares, queden sin consignación.

En los delitos cometidos por organizaciones criminales hay un reparto de roles, en una estructura funcional, donde normalmente son unos sujetos los que planifican y otros los que ejecutan las 
órdenes. Normalmente los sujetos que planifican son los que dirigen la organización y los sujetos que intervienen en las esferas más bajas de la organización son precisamente quienes ejecutan el plan criminal. No coincide quien realiza materialmente los hechos con quien concibe el plan criminal. Presentándose dificultades para aplicar el Derecho Penal, porque quienes realizan materialmente el delito son en realidad quienes menos poder de decisión han tenido sobre la ejecución final del mismo. ¿Cómo hacer responder penalmente a los que dirigen las organizaciones criminales, ya que no intervienen directamente en la realización de los hechos concretos que llevan a cabo otros? Pero son quienes asumen el diseño, planificación y control final de su realización. Se realiza la tesis del "autor detrás del autor", donde el hombre de atrás es realmente el responsable.

En el ámbito internacional se están aplicando medidas para atajar la financiación de las organizaciones terroristas. La Unión Europea (UE) está contemplando medidas para "congelar las cuentas", "prohibir los movimientos de capitales" de personas y organizaciones consideradas terroristas o que colaboran con el terrorismo. Sin duda, desde el punto de vista de la eficacia este tipo de medidas resultan bastante justificables, pero desde el punto de vista de las garantías resultan más bien muy cuestionables. ¿Con qué criterio se establece el carácter terrorista de la organización? ¿Cómo se establecen las organizaciones colaboradoras con organizaciones terroristas?

Ante el extraordinario poder criminógeno que están teniendo las organizaciones criminales el reto del Derecho Penal es idear mecanismos más idóneos para hacerles frente dentro de un marco de racionalidad y efectividad. Se trataría de rediseñar criterios de imputación penal para los ilícitos cometidos en el seno de las organizaciones. La lucha contra el crimen organizado en un mundo globalizado no puede responder simplemente con el instrumento penal. La base social que genera las distintas formas de tráficos ilícitos junto con la radicalización de las desigualdades y el afán desmedido de riquezas tiene que ser afrontado con múltiples políticas sociales y económicas.

La lucha contra la criminalidad organizada no debe ser utilizada para acallar a las organizaciones que discrepan con el orden mundial imperante o imponer el estado de sitio a la sociedad civil. El respeto al derecho de asociación, a la libertad de pensamiento, expresión y crítica deben protegerse con cautela.

No se trata de reducir el problema a la intervención penal, sino diseñar un programa Integral de Política Criminal con base en un estudio científico de las distintas formas de criminalidad organizada, para realizar planteamientos apropiados de prevención. El futuro de la lucha contra las organizaciones criminales pasa por estructurar mecanismos de imputación comprendiendo la violencia colectiva, la responsabilidad organizativa, la actitud criminal del grupo y sus vinculaciones con la criminalidad de empresa. (Zúñiga, 2002 52-54). 


\section{EL CRIMEN ORGANIZADO NORTEAMERICANO}

La falta de oportunidades de empleo, aunado a la marginal estructura socioeconómica política, y debido a que los negocios legítimos están monopolizados por unos pocos, la gran mayoría de población se convierte en asalariada, en verdaderos ejércitos de esclavos trabajando por salarios ínfimos en cárceles o cadenas comerciales que tienen como alternativa su afiliación a la delincuencia. Los primeros grupos organizados, y con el amparo de la violencia, comienzan a socavar, reprimir, acosar, y amedrentar a sus compatriotas que van llegando. Esta práctica la realizaba la banda conocida como La Sociedad de la Mano Negra, una forma elegante de chantaje dirigida contra el trabajador inmigrante (Silica, 1974). El nombre provenía de unas cartas amenazadoras firmadas por un sencillo dibujo de una mano negra, en el que se exigía dinero bajo amenaza de muerte, rapto o mutilación de los hijos de la víctima de la extorsión.

En 1930, el Departamento del Tesoro creó la Unidad contra las Drogas, que posteriormente se reestructuraría en la Oficina Federal de Narcóticos y en la era de Nixon se convertiría en Oficina de Narcóticos y Drogas peligrosas. Estas áreas más tarde formarían en el año de 1973 la Drug Enforcement Administration (DEA..). Agencia del Departamento de Justicia dedicada a la lucha contra el contrabando y el consumo de drogas en los EUA. Responsable de coordinar y perseguir investigaciones antidrogas en el extranjero. En los esfuerzos para controlar y vigilar la delincuencia organizada se suma a la DEA el Federal Bureau of Investigations, creación de uno de los grandes magos de la administración de la justicia John Edgar Hoover quién asumió el cargo de director en 1924 a los 29 años de edad y dejó su cargo en 1972 cuando murió. Richard Nixon dijo: Si él estuviera vivo nada de esto hubiera pasado, refiriéndose al escándalo de Watergate que le costó la presidencia. Por supuesto están grandes personajes de cuello blanco como Richard Mellon Scaife, quién encumbró a los Bush en el poder, Henry Kissinger en el mundo diplomático, William Colby en servicios de inteligencia con el temible proyecto Phoenix que causo más de 20.000 muertes en Vietnam. En el mundo bélico militar destacan personajes como William Forrester, Curtis LeMay, Robert MacNamara, más recientemente, los generales David Petraeus y Richard Perle.

El crimen organizado ha gobernado el bajo mundo de la política. Con el tiempo apareció un incremento en las conexiones políticas, las relaciones con funcionarios públicos, de todos los niveles. Siempre ha existido, bajo la mesa, esta comunión substancialmente proveniente de las donaciones para sufragar los enormes gastos económicos que se deben efectuar en las campañas políticas. La corrupción es un cáncer que carcome fácilmente a cualquiera; o se estaba adentro y se apoyaba o simplemente quedaba fuera².

2. Un ejemplo demoledor de que los políticos eran los que realmente gobernaban el bajo mundo, se aprecia en la caída de Al Capone. El crimen en Chicago había llevado a la quiebra a la ciudad; la policía estaba corrompida hasta la medula, el salario se encontraba por los suelos, existía un endeudamiento oficial caótico, la extorsión alcanzaba a grandes compañías, se recopiló una lista de 91 sindicatos y asociaciones que habían caído bajo el poder de los 
La delincuencia tiene sustento en toda una red que ejerce una actividad especializada, prototipo de crimen; el asesinato, como actividad necesaria para el mantenimiento del terror u opresión y básicamente del temor al poder. La historia nos muestra infinidad de casos; periodistas, opositores, incluso presidentes han sido sus víctimas.

Los métodos de la delincuencia organizada van desde los más simples como el tiro por la espalda, en la cabeza o en el pecho, en una calle desierta. O ser baleado en el interior del carro en plena circulación por una avenida, hasta formas, que siempre causaban terror, como arrojar a la victima a la cal viva o meterlo en un bote con cemento hasta los pies y arrojarlo al mar o enterrarlo o quemarlo vivo. Todas las formas valen en esa guerra y también sus artefactos desde la pistola, la metralleta, la soga o cuerda, hasta la utilización de las dagas, el cuchillo, el veneno, el acido, el fuego, o las bombas.

La avaricia por el dinero llevó a los jefes a construir grandes casinos, bajo el resguardo de hoteles y entre cortinajes de terciopelo, pisos alfombrados, habitaciones privadas lujosamente adornadas, ostentosos restoranes, en medio de salones lujosos, los juegos se llevaban a cabo noche tras noche, dando rienda suelta a todo tipo de juegos de azar, las veinticuatro horas del día; allí no se descansaba, siempre se trabajaba, y se ganaba. Gracias al ímpetu del fundador del crimen organizado en California, el gánster Buggsy Siegel, se crearían el Frontier Club y el flamante Flamingo Club de Las Vegas, Nevada; El Riviera en Cuba, donde ciudadanos dignos y respetables dejarían su dinero de toda una vida de trabajo y esfuerzo. Nadie sabrá nunca el número exacto de hombres que con el juego de apuestas quedaron completamente en la ruina.

A la par del juego, el contrabando de drogas y la trata de blancas tomaron fuerza; las mafias procuraban distribuir el opio, heroína, cocaína, cannabis, proveniente de Colombia, Afganistán, Turquía y Grecia; lo hacían llegar a México y el contrabando entraba a los Estados Unidos. En mucho la guerra de sangre que vive México es por el conflicto del narcotráfico. A partir de julio del 2011 este es el sexenio de los 50.000 muertos. Se han documentado 50.490 asesinatos relacionados con el crimen organizado; la cantidad incluye lo que el gobierno federal clasifica como ejecuciones enfrentamientos y homicidios-agresiones. (Mendoza, 2011; 4)

La criminalidad es poderosa porque la raíz básica del crimen organizado es la protección política. Mientras los políticos, funcionarios y cualquier servidor público de jerarquía hagan negocio

extorsionadores. Esto trajo como consecuencia que un grupo de ciudadanos acaudalados que habían aportado fondos a la campaña electoral presidencial, como Julios Rosenald de Sears Roebuck, y con negociaciones en el partido republicano, pidieron la intervención del presidente. Alphonso Capone, conocido por Scarface, que controlaba el reino gangsteril, un buen día es acusado por evasión de impuestos, y una vez capturado por agentes del Departamento de Justicia a cargo de Elliot Ness, es sentenciado a cumplir una condena de diez años de prisión en Alcatraz, nunca seria cumplida, moriría el 25 de enero de 1947, en Palm Island, Florida, de sífilis, a los 48 años de edad. 
o tenga contubernios o mantengan relaciones con los delincuentes no dejará de existir y florecerá por doquier.

El número de delitos cometidos por el crimen organizado ${ }^{4}$, cuyos autores 5 muchas veces empezaron en la juventud, iban desde la realización de agresiones que causaban lesiones, hasta la comisión intencional de homicidio, pasando por la vagancia, el robo con violencia, el contrabando de alcohol, el robo de joyas, la posesión de armas prohibidas, el asalto a bancos, la incitación a huelgas, el manejo de centros donde ejercería la prostitución, el mantenimiento de casas de juego clandestino, el control del tráfico de narcóticos, las apuestas clandestinas en las carreras, los préstamos usurarios, la evasión de impuestos sobre la renta, el manejo de sindicatos, la extorsión laboral e industrial sobre el comercio de legumbres, harina, en la industria del vestido, del transporte, $y$ en las ramas de restoranes y tiendas diversas, y la fuga presidiaria.

Con el paso del tiempo la Unión Italoamericana llamada La Cosa Nostra, La cosa de nosotros, se convirtió en una empresa con estructura compleja y funciones claramente organizadas, de gran envergadura criminal, tanto así que ayudaría a los intereses norteamericanos en su lucha contra el comunismo, durante la Segunda Guerra Mundial, y en el que la $\mathrm{ClA}^{6}$ hubo patrocinado directamente el desarrollo de organizaciones criminales locales para fomentar los intereses de la

3. En 1959 se promulgaría una ley sobre información y publicación de relaciones laborales, a fin de limpiar los sindicatos; esto trajo como consecuencia que en 1977 se aprobara la ley de control del crimen organizado.

4. Sobre la forma y la dinámica de estas operaciones, ver Los ejecutores, la alianza secreta entre el gobierno de Estados Unidos y el crimen organizado, Michel Mila. El Astuto, como el FBI desmembró a la mafia de E.U., Joseph D. Pistone y Richard Woodley, ambas de ediciones Selector, México, 1990.

5. La lista de los más buscados del FBI de los años veinte a cincuenta incluyó a: Harry Millman, Caryl Chessman, Louis Capone, Albert Anastasia, Joseph Doto Joel Adonis, Northern Mob, los hermanos Fischetti, Tony Gizzo, Frank Costello, el "primer ministro", El Purple Gang, Abe "kid Twist" Reles, Johnnie Torrio, Alfred Al Capone o Al "Scarface", Willie Suton, Red Alpert, Happie Maione, Frankie Yale, Dion O Bañón, Antonio Carfano, Carlo Lucania, Charly "Lucky" Luciano, Gorge Ufner, Arnoldo Rothstein, Waxey, "el pegajoso" Gordon, Meyer Lansky, Legs Diamond, Dany Phil Pastel, Charlse Salomón, Longy Zwillman, Dutch Schultz, Salvatore Marrizano o Mazarano, Vito Genovese, Vicente Alo, Moey Dimples, Abner Zwillman, Joe Liberito, Angelo "Julie" Catalana, Sholem Bernstein, Blue Jaw Magno, Anthony Fabrizzo, Ciro Terranova, Mickey Cohen, Francis Utley, Louis Buchalter, King Solomon, Nig Rosen, Yasha Katzenburg, Tommy Luchese, Gerald Chapman, Jack Dragman, Albert Florido, Jimmy Feraco "Cara Sucia", Thomas Cassara, John Argensola, Mert Wertheimer, Frank Nitto, William O Dwyer, Frank Ericsson. Para una breve visión sobre estos personajes puede consultarse Morder, INC, de Burton B. Turkus y Sid Feder, Ed. Bruñera, Barcelona, 1960.

6. "La Central Intelligence Agency, -Agencia Central de Inteligencia-, fue creada en los Estados Unidos en base a la Ley de Seguridad Nacional, aprobada en 1947 y ampliada en 1949 con una ley complementaria. La CIA es el órgano supremo para asuntos de espionaje, asesorar al gobierno en lo relacionado con estas actividades y coordinar el funcionamiento de otros órganos de espionaje, con A2 Air Force Intelligence, CIC Counter Intelligence Agency, FBI Federal Bureau of Investigation, G2 Army Intelligence, NSA Nacional Security Agency, ONI Office of Naval Intelligence, y también la investigación de los ensayos nucleares de otros países, llevada a cabo por la Atomic Energy Commission. La actividad de la $\mathrm{CIA}$ es supervisada en nombre del Presidente de los Estados Unidos por el Secretario de la Defensa, el subsecretario para asuntos políticos, el Director de la CIA, y el Jefe del Estado Mayor". Enciclopedia Internacional y de Naciones Unidas, Fondo de Cultura Económica, México, 1976, p. 748. 
política exterior, como en el caso de la ocupación de Sicilia por las fuerzas aliadas, del control del puerto en Marsella, Francia, en la ocupación nazi, para el cultivo y transporte del opio que se hace en Vietnam, Bangkok y Tailandia, y financiar así las operaciones de contrainsurgencia, y apoyar del régimen de Batista en Cuba. ${ }^{7}$

Ahora es más evidente que la mafia participó en el asesinato de John F. Kennedy. Lo que realmente me causo impacto es un relato de un señor que cerca de las ruinas de Chichenitza en Yucatán me platicó una anécdota que me dejo helado: Resulta que cuando él era niño vivía en una ex hacienda cercana a la ciudad de Mérida donde conoció a un extraordinario francotirador inglés que podía matar a una gallina cabeceando a docenas de metros de distancia. Este extraordinario francotirador del ejército inglés estaba esperando la llegada de Lee Harvey Oswald que provenía de sus entrenamientos en Cuba, para recibirlo y protegerlo en México para luego introducirlo a los EUA. Este espeluznante relato que me fue conferido demuestra que los servicios de inteligencia estadounidense y británicos estaban enterados y participando activamente en la preparación del asesinato del presidente John F. Kennedy.

Los Estados Unidos de América enfrentan graves situaciones de delincuencia, ya que según datos del reporte del National Drug Intelligence Center, el FBI afirma que operan en el país cerca de más de ocho mil bandas delictivas, principalmente dedicadas a la distribución de drogas. Existen 24 principales familias, cada una tiene un jefe don, un subjefe sottocapo, un consejero o asesor consigliere tenientes caporegine, jefes de sección, y soldados o pistoleros. ${ }^{8}$

La mafia norteamericana opera celularmente, en base a la organización criminal llamada, La Cosa Nostra pero hay que agregarle el funcionamiento de la Mafia Siciliana, la Andrangheta, originaria de Calabria, y la Camorra, surgida en Nápoles. Todos estos grupos operan de manera macro delincuencial a nivel mundial. Además, se debe sumar las acciones con las micro bandas que se dedican en su territorio a cometer toda clase de fechorías, dominando a los de su propia raza; nos referimos a las pandillas integradas por negros, chinos, chicanos, vietnamitas, japoneses, mexicanos, coreanos, tailandeses, camboyanos, jamaicanos y los grupos marginados de Centroamérica como los salvadoreños, guatemaltecos, hondureños y nicaragüenses, que operan preferentemente en su barrio y por las calles desiertas.

Los líderes de la mafia La Cosa Nostra están en las familias de los Bonnano, fundada por Joe Bonnano y encabezada por Joseph Máximo y Salvatore Vitale; la Colombo, fundada por Joe Profaci y encabezada por Alphonso Persico; la Gambino; fundada por Vince Mangano, Carlo

7. Se consolida la teoría de que en los años sesenta "La Cosa Nostra" tendría relaciones con los grandes jefes de la mafia, como Sam Giancana, Carlo Márchelo y Santo Traficante, para participar en el homicidio del presidente John F. Kennedy. Véase El imperio de la Habana, Enrique Cirules, Ed. Casa de las Américas, La Habana, Cuba, 1993.

8. Consultar. El último mafioso, Ovid Demaris, Lasser Press Mexicana, México, 1981. Rey de la mafia: Carlo Gambino, David Hanna, Organización Ed. Novaro, México, 1976. 
Gambino, Paul Castello y John Gotti, encabezada por Peter Gotti; y la Genovese, encabezada por Dominio Quiet Dom Cirillo.

Una de las medidas adoptadas por los norteamericanos para incriminar a miembros de la delincuencia organizada lo es la figura jurídica que llaman conspiración. Esta consiste en contemplar como delito que una persona colabore con una o más personas con el fin de cometer un crimen. La figura de la conspiración, ahora entendida como una forma de participar activamente en la comisión delictiva por medio de la cooperación o colaboración, tuvo raíces relacionadas, dentro de la guerra fría, con los Estados que practicaban regímenes autoritarios, totalitarios, tales como el comunismo, el fascismo y el nazismo. La acusación de conspiración era empleada para instigar a grupos étnicos y foráneos, con una especie de ideología racista, para estigmatizarlos como atentadores de la democracia y el american way of life.

El crimen organizado en los Estados Unidos de América tiene raíz en el tráfico y consumo de drogas, incluyendo delitos de jurisdicción estatal como el homicidio, el robo, la violación, la extorsión, la usura, la riña, la portación de armas, el robo de vehículo, el asalto y otros diversos delitos contemplados como graves en el orden federal. Los delitos de delincuencia organizada son el lavado de dinero, el control de sindicatos, el control e injerencia en actividades económicas, el secuestro, el juego ilegal, el incendio intencional, el robo de cargamentos interestatales, el soborno, la extorsión, el manejo de material obsceno, la prostitución, las transacciones crediticias por medio de extorsión.

El principal ordenamiento jurídico con que cuentan los Estados Unidos para combatir el crimen organizado es el Estatuto denominado RICO (Racketeer Influenced and Corrupt Organizations) que conforma varias disposiciones contenidas en la Ley para el Control del Crimen Organizado. (Reuter, 1995). Este instrumento implica una labor de inteligencia sobre los aspectos más directos, complicados y graves de la criminalidad organizada. El estatuto contempla una figura que reúne lo que nosotros ubicamos como Delincuencia Organizada, es decir, ellos anteponen la figura empresa, para designar a cualquier individuo, asociación, corporación, sociedad o grupo de individuos asociados legal o ilegalmente. Otros de los medios con los que el gobierno estadounidense se auxilia son: el sistema de declaración de culpabilidad, con su beneficio de lograr una disminución o sustitución en su sentencia. El sistema de inmunidad. El empleo de las acciones u operaciones encubiertas. El pago y protección de soplones. La utilización de la vigilancia electrónica como intervención telefónica.

\section{EXCESOS Y EXCENTRICIDADES DE LA ÉLITE DEL PODER: LOS AMOS DEL MUNDO}

En la primera década del siglo XXI se forjo una nueva élite de poder que aparece con el nombre de Los amos del universo que está definiendo el nuevo orden mundial de acuerdo con sus intereses. La existencia de esa nueva élite proviene fundamentalmente de cuatro fuentes origi- 
nales: 1) Hermandades y Sectas 2) Líderes corporativos 3) Estrategas intelectuales y militares 4) Los muy ricos. En esta categoría se encuentran los jeques árabes, dueños de la mayor parte del petróleo del mundo; en este apartado mostraremos su vida de excesos y excentricidades.

Cuando George W. Bush estudiaba en Yale se afilió a Skull and Bones una sociedad secreta a la que pertenecía su padre y su hermano Prescott. La secta era el ámbito donde se forjaban los vínculos entre hombres que dirigirían los bancos de solera y los bufetes clásicos, destinados a convertirse en los sabios de Washington. Era la alta sociedad del este: los Bundy, los Buckley, los Arriman y los Taft. Entre los miembros de dicha sociedad figuraban tres presidentes, varios jueces del Tribunal Supremo, senadores estadounidenses, secretarios de estado, consejeros de seguridad Nacional, los fundadores de Time Inc., de la CIA, y muchos más. (Unger, 2004: 49)

La riqueza de algunos jeques es tal que con su riqueza se podría acabar con el hambre en algunos de los países más pobres del planeta. Su riqueza no solo les ha permitido vivir en la opulencia, llegan a los excesos y practican excentricidades. A continuación mencionaremos los excesos y excentricidades de algunas dinastías más famosas en el mundo derivada de la excesiva riqueza.

El Palacio Istana Nurul Imán se encuentra en Brunei y actualmente es la residencia oficial del Sultán de Brunei, Hassanal Bolkiah Muizzaddin Waddaulah. El sultán de Brunei es uno de los hombres más ricos del planeta. El palacio Istana Nurul Imán se encuentra en la colina que hay a orillas del río Brunei, al sur de la ciudad la capital de Brunei; es el palacio más grande del mundo con 1788 habitaciones, 257 baños y un área libre de 200.000 metros cuadrados. Cuenta con varias piscinas, establos, garajes y varias salas utilizables para las fiestas o eventos sociales del Estado.

El sultán Hassanal Bolkiah Muizzaddin Waddaulah gasto 7.14 millones de euros el día del cumpleaños -veinticinco-, su hijo el príncipe Aziz, con una actuación privada Michael Jackson. El sultán de Brunei es la máxima autoridad de un pequeño emirato que cuenta tan solo con 375.000 súbditos, ubicado al noroeste de Malasia y de la isla de Borneo -rico en petróleo- por lo que su fortuna personal se calcula en más de 14.300 millones de euros, según la revista Forbes.

El sultán Brunei, Hassanal Bolkiah, posee una flota de automóviles de súper lujo con cinco mil vehículos, muchos no se usan y están en resguardo de hangares o almacenes lujosos con climatización para su cuidado. Sus automóviles están adornados por metales preciosos como el oro y los brillantes, el auto que se ocupa en las bodas reales posee un $70 \%$ de sus partes en oro y diamantes.

Algunos de los automóviles de los garajes del Palacio se usan en contadas ocasiones, y es tal el exceso en el cuidado para estos vehículos que son transportados en barco periódicamente a 
Inglaterra, para que les sea cambiado el aceite y realizada una puesta a punto en la empresa productora. La última adquisición del sultán de Brunei Darussalam fue 12 unidades del modelo Rolls Royce Phantom V12, con un valor aproximado de 7.3 millones de euros, los cuales fueron equipados con puertas de cierre eléctrico, vidrio a prueba de balas, carrocería blindada, un sistema de cine con sonido de última generación, navegación satelital y un panel de instrumentos con diamantes incrustados. Cuenta con una decena de Rolls Royce y una serie muy especial de Ferrari, los cuales son modelos únicos en el mundo. Las modificaciones son realizadas por los exclusivos diseñadores italianos Pininfarina y Michelotti.

El sultán Hassanal Bolkiah de Brunei tiene una serie de palacios aéreos, no solo basta con todos los automóviles que colecciona. Recientemente compró un Airbus A 340, remodelada en Waco, Texas. En el avión parte de la grifería es de oro puro y el lujo y los excesos saltan a la vista. El avión costó cerca de U\$ 100 millones y las mejoras y arreglos que se le realizaron implicaron otros 120 millones adicionales. El Sultán habría encargado ya un nuevo avión privado, el Airbus A380, al que se seguramente le hará algunas modificaciones de acuerdo a su exigente gusto.

El rey Abdul Aziz, fundador de la Arabia Saudita moderna, tuvo 43 hijos, y la expresión siete sudaríes- se refiere a los siete hijos de su esposa predilecta, que incluyen al rey Fahd; ministro de defensa, el príncipe Sultán; Gobernador de RIAD, el príncipe Salman; ministro del interior, el príncipe Nayef; Director de negocios, el príncipe Abdulrahman, el príncipe Ahmed y el príncipe Turki Bin Abdul Aziz. Adicionalmente, se encuentra el príncipe Turki Bin Faisal jefe del servicio de inteligencia que en 1978 reclutó a Osama Bin Laden para gestionar financieramente las operaciones de la CIA en Afganistán. La CIA invirtió 2.000 millones de dólares para lograr el fracaso de la Unión Soviética. Bin Laden gestionaba las operaciones financieras en un fichero informático llamado Al Qaeda La base de datos. (Odalric de Caixal, 2009: 3)

Cuando estudiaba en Líbano Osama se portaba como un play boy, conducía un Mercedes amarillo, llevaba trajes a la medida y tomaba Dom Perignon y Johnnie Walker etiqueta negra en el Crazy Horse y el Casbah. Se redimió en 1977 cuando él y su hermano Salem se unieron a las masas para llevar a cabo los exigentes ritos de la peregrinación a la Meca. Osama visitó la cueva del monte Hira, cerca de la Meca, donde se dice que Mahoma recibió las revelaciones divinas. Según Robinson, la experiencia conmovió profundamente a Osama que vendió su Mercedes, se dejó barba y se sumergió en los estudios islámicos como nunca hasta entonces. (Unger, 2004: 111).

Esta experiencia puede ser considerada como un proceso de predestinación donde el líder guerrero asume la defensa de los pueblos árabes y de los principios del Islam. La máxima ofensa que genera occidente es a la violación de sus principios éticos, culturales y religiosos de la comunidad árabe. Esa es la causa por la que Al Qaeda ataca a occidente y a sus aliados. A raíz 
del asesinato de Osaba Bin Laden en Paquistán han prometido realizar 100 ataques terroristas para vengar la muerte de su líder.

El jeque Sheik Mohammed Bin Rashid al-Maktoum, que tuvo la idea de construir una serie de islas artificiales en Dubái (Emiratos Árabes) que se sumarán a la línea costera de Dubái unos 520 kilómetros más. Las islas más chicas son las que están formando una palmera, la conocida Palm Islands, que consta de 17 ramas, en cada rama se edificaron residencias lujosas, lujosos hoteles e incluyendo el Hydropolis, primer resort submarino, con playas privadas, cuenta con un túnel submarino que solo lo pueden visitar todos aquellos que puedan solventar una de estas residencias. Los residentes tendrán acceso al Queen Elizabeth 2, uno de los cruceros más majestuosos del mundo, como hotel flotante atracado a uno de los cayos.

Actualmente se trabaja en un archipiélago de islas artificiales que semejará un mapa de la tierra, y se Ilamará simplemente El Mundo. El proyecto fue construido en el 2001 por el Jeque Mohammed Bin Rashid al Maktoum el príncipe de Dubái, un apartamento que hace poco costaba 200.000 mil euros hoy día duplico su valor con creces. Posee un aeropuerto que se distingue por el lujo y esplendor donde llegan celebridades como Beckham o Clinton que ya cuentan con una propiedad en el lugar.

El jeque de los Emiratos Árabes Unidos Hamad Bin Hamdan Al Nahyan, decidió escribir su nombre en las arenas de una isla de su propiedad. El nombre HAMAD quedó tatuado en el piso del desierto y es visible desde el espacio, mide 3,5 kilómetros desde la $H$ hasta las $D$ y se la puede divisar al acudir a Google Maps. Después de hacerlo, los ingenieros empezaron a dirigir las aguas del golfo pérsico para llenar los surcos en forma de letras. Hamad lo hizo así para evitar que tormentas de arena puedan borrar la obra. Con una fortuna estimada en USD 21 mil millones empleó a obreros por semanas enteras para cavar los surcos que formarían sus letras en la isla Al Futayasi, que tiene 50 kilómetros cuadrados de extensión. La obra permite que en las dos primeras letras, sus amistades puedan navegar sobre ellas en un yate.

En 1993, la autoridad religiosa suprema de Arabia Saudí, el jeque Abdel-Aziz Ibn Baaz, emitió un edicto o fatwa declarando que el mundo es plano. Todo el que crea que es redondo no cree en Dios y debe ser castigado. No deja de ser irónico que la lúcida evidencia de que la Tierra es una esfera, reunida por el astrónomo grecoegipcio del siglo II Claudio Ptolomeo, fuese transmitido a Occidente por astrónomos musulmanes y árabes. El jeque después de viajar al espacio y constatar que la Tierra era geoidal eliminó tal edicto judicial.

Otro excéntrico es Andrei Melnichenko, uno de los multimillonarios rusos de mayor renombre en su país: 36 años, casado, una de las 200 personas más ricas del planeta y una fortuna que alcanza los 4.600 millones de dólares. Su nuevo Yate se ha convertido en todo un símbolo en Rusia. Unos aseguran que es un buque de guerra que, además de tener los cristales tintados, posee inhibidores de radar, otros afirman que es sumergible. 
El yate, con una longitud de eslora superior al largo de un campo de fútbol, se encuentra en el ranking de los diez yates privados más largos del mundo y le ha costado 300 millones de dólares. La atención del barco es el elevadísimo, consume diesel por 690 galones la hora y permanentemente hay que mantener su sistema tecnológico de pantallas y radares satelitales.

Uno de los hombres más ricos de China es el millonario Huang Qiaoling, propietario de un auténtico imperio de empresas del sector turístico; posee una réplica exacta de la Casa Blanca, la residencia del presidente estadounidense. El propietario la construyó en su ciudad natal, Hangzhou y le ha costado 10 millones de dólares. El exterior e interior es réplica exacta; desde el sofá barroco, que vale 60.000 dólares y tiene el sello presidencial en cada una de las alfombras, y la silla de la mesa que vale 8.000 dólares.

La Riviera maya es uno de los destinos turísticos más elegido por las personas más ricas del mundo. Un duque italiano que vacacionó en Cancún, envió con tres meses de anticipación una avanzada de colaboradores, quienes se dieron a la tarea de seleccionar el hotel y verificar su seguridad. La comitiva solicitó la suite presidencial, una de las más lujosas y caras del hotel, en promedio cinco mil dólares la noche. La suite presidencial con todas las comodidades y servicios que un cliente puede demandar para los gustos de un duque no es suficiente. Se cambio toda la suite; muebles, colchones, sábanas, cortinas; posteriormente, llegaron de Italia una serie de decoradores para hacer cambios más minuciosos, desde el color de la pintura, así como ceniceros, vasos y vajillas. Todo fue traído del viejo continente, la pintura y el mobiliario se fletaron por barco. Sólo el personal de confianza al servicio del duque pudo tener acceso a la suite desde tres meses antes. En el verano de 1997, tras cuantiosos gastos por el pago de alquiler, mobiliario y estancia de su personal, el duque italiano, arribó a Cancún con un grupo de chefs, amas de llaves, mayordomos y demás personal dedicado a mantenerle al tanto de negocios y demás ocupaciones que requeriría durante una estancia no mayor a 15 días. Tras su partida, a petición del gerente del hotel, la habitación fue dejada tal y como se redecoró, ni un solo detalle fue llevado de regreso con sus propietarios.

Aristóteles Onassis quien procreó dos hijos, Alexander y Christina, gustaba de la frase: debemos liberarnos de la esperanza de que algún día el mar esté calmado. Hay que aprender a navegar con vientos fuertes. Y así fue su vida, un mar tempestuoso. Su debilidad, las mujeres elegantes como Maria Callas y Jacqueline Kennedy, su pasión su hijo Alexander que murió después de una agonía por quedar en estado vegetativo después de un accidente en hidroplano. Se sabe que mando construir un mausoleo de mármol blanco en la isla de Scorpios donde enterró a su hijo y acudía frecuentemente a solas para rezar junto a su tumba. Christina se caso en cuatro ocasiones, tuvo una hija llamada Athina Rousse, quien es ahora la única heredera de la fortuna. Christina apodada la infeliz niña rica fue diagnosticada con depresión, bipolaridad, desequilibrio emocional; murió en 1974 por una sobredosis de pastillas mezcladas con alcohol a los 37 años. El cantante español Joaquín Sabina le dedicó en 1990 la canción Pobre Cristina, por la que mereció una demanda judicial. En 
1975 muere el magnate Aristóteles Onassis, con diagnóstico de neumonía y la constante depresión que sufría por la muerte de su hijo. Actualmente los tres descansan en paz en la Isla Scorpios.

\section{DUBÁI: LA CIUDAD DEL PARAISO EN LA TIERRA}

En los Emiratos Árabes Unidos se ha construido unas de las ciudades más excéntricas y alucinantes del mundo: Dubái. El poder de los petrodólares la desarrollo de manera extraordinaria en los últimos años, atrayendo a todos los millonarios y nuevos ricos del planeta. Aquí fue donde se pudo ver a Michael Jackson vestido de mujer árabe paseando por un centro comercial. Donde antes sólo había un desierto hoy abundan los rascacielos -entre ellos el más alto del mundo, aún en construcción-, los campos de golf y todo tipo de excentricidades.

Su costa, moldeada al antojo de los jeques y magnates, plagada de islas artificiales con formas inverosímiles como palmeras y hasta un mapamundi. Estas islas albergan mansiones paradisiacas, sólo al alcance de pocos bolsillos como el de David Beckham. Aquí se encuentra el primer hotel que consiguió lucir siete estrellas con su restaurant flotante en las nubes y la cancha de tenis donde jugaron Federer y Agassi en su cúspide. Una foto publicada recientemente devela la ciudad envuelta en la niebla, sobresalen torres de rascacielos y grúas que construyen más rascacielos.

El desarrollo en Dubái ha sido estratosférico, es una gran obra de arte en construcción, donde casi todos los proyectos que han prometido están en obra o en maqueta. Este emirato, que buscando alternativas de riqueza aparte del petróleo opto por convertirse en un paraíso turístico, comercial, de salud y paraíso fiscal para inversionistas, sigue al pie de la letra su Plan Estratégico 2015 que refleja la visión de Shoah Mohammed Bien Rasí Al Maktoum quien frente a cada proyecto, por excéntrico que parezca, siempre dirá "why not, let's do it" en la medida que le garantice flujo de turistas e inversionistas.

En Dubái aparecen excentricidades como la Isla de las Palmeras, la torre más alta del mundo, el hotel más lujoso del mundo, un Mall con una cancha de esquí en el desierto, entre otras. Y parece que su plan de generar una oferta para una demanda excéntrica les funciona, hay credibilidad de los mercados internacionales para desarrollar nuevos proyectos que asombran y sorprenden.

Aprendieron como ganarle terreno al mar y al desierto. Un desértico emirato de $70 \mathrm{Km}$ de costa se convertirá en unos pocos años en un parque de diversiones más grande que Hong Kong, un Waterfront más grande que Singapur, y una colección de torres y edificios con una arquitectura con los bosquejos más osados donde la imaginación de los arquitectos encuentran terreno fértil para convertirse en realidad. 
En Dubái sólo el 20\% de la población es nativa y cuentan con innumerables privilegios como la entrega de terrenos, casas, bonos por matrimonio, educación, salud y servicios básicos gratuitos y obviamente exención de todo tipo de impuestos.

El resto de la población corresponde a expatriados, principalmente obreros hindis y pakistanís que han hecho de Dubái una ciudad con un look \& feel con autopistas y rascacielos de muro de cortina que podría perfectamente ser Miami, Las Vegas o Singapur, y con un estilo árabe que parece más bien una imposición forzosa para que el turista se sienta en un mundo árabe más del estilo Epcot Center.

En Dubái el idioma oficial es el inglés, y es la única ciudad árabe del mundo donde no flota en el aire la llamada a la oración de los muecines que caracteriza a las ciudades como Damasco, Ammán o El Cairo, para evitar que el turista sienta presiones respecto de lo peligroso que es el Islam. Para aumentar la sensación de seguridad, parece no haber policía. Es un lugar donde se puede caminar de noche sin problemas, tanto hombres como mujeres solas y vestidas en la usanza más occidental.

Con los mesiánicos proyectos como "Where Vision Inspires Humanity" de Nakheel o "For the Good of Tomorrow" de Dubái Holding, no sería de extrañar que el próximo proyecto de Sheihk Mohammed se llame "The Breeze". Una cúpula gigante que protegerá todo el emirato de los rayos UV y lo climatice. Cualquier proyecto que garantice más turistas e inversiones, seguramente decidirá: "Why not? Let's do it".

Recientemente se presento el proyecto que bien podrían construirse en Dubái, pero lo insólito es que pretende construirse en España. Se llama Isla Luna o La Luna de Valencia. Es una isla artificial, de forma circular, frente a la Playa de la Malvarrosa de la capital valenciana. A diferencia de las islas artificiales de Dubái, incluye mansiones de lujo y un barrio entero con todos sus servicios. Para concluir este parque temático de Calatrava sólo falta levantar tres rascacielos.

\section{CONCLUSIONES}

- $\quad$ No se trata de parcializar el problema en la intervención penal, sino diseñar un programa Integral de Política Criminal con base en un estudio científico de las distintas formas de criminalidad organizada, para realizar planteamientos apropiados de prevención.

- En la actualidad, aparece una verdadera industria del crimen, presente en varios países como las mafias lograron infiltrarse en las relaciones sociales y políticas. Con una mayor contaminación de empresas legales para mezclar el capital ilícitamente obtenido en el capital sano de empresas privadas. 
- La criminalidad es poderosa porque la raíz básica del crimen organizado es la protección política. Mientras los políticos, funcionarios y cualquier servidor público de jerarquía, hagan negocio o tenga contubernios o mantengan relaciones con los delincuentes no dejará de existir y florecerá por doquier.

- Tendencias principales de la financiación de las guerras. Los grupos rebeldes dependen principalmente de las siguientes actividades económicas:

* El control y la explotación ilegales de los recursos naturales legales, los cuales son comercializados en mercados locales e internacionales.

* El cobro ilegal de impuestos y el control de mercados ilegales con altos márgenes de ganancia, tal como el de la cocaína, la heroína y el cannabis.

* El control local y regional de la economía subterránea por medio de la producción y el tráfico ilegal de bienes de consumo o de servicios legales. Robo, extorsión y secuestro.

\section{BIBLIOGRAFIA}

- $\quad$ CNN. (18/VIII/2011), http://mexico.cnn.com

- Corigliano, Mario Eduardo. (2005), Principios de criminología. En www.monografias.com/ trabajos/14/delitcorrup/shtml

- $\quad$ El Universal. (6/VI/2011), www.eluniversal.com.mx/notas/.

- $\quad$ Escribá-Folch, Abel. (2008), Maten al León. El castigo a los dictadores salientes.Rev. Mexicana de Sociología. 70. №3. UNAM-IIS. México.

- Gage, Nicolás. (1978), Mafia, sociedad del crimen organizado. Ed. Diana, México.

- Guáqueta, Alexandra (2003), "La economía política internacional de los conflictos internos". Rev. Convergencia №31 Enero-Abril año 10. Fac. de Ciencias Políticas y Sociales. Universidad Autónoma del Estado de México. Toluca, México.

- Jiménez, Eugenia. (4/III/2010), Periódico Milenio. México. www.milenio.com/cdb/doc/ noticias2011.

- $\quad$ Laurent, Eric. (2004), El mundo secreto de Bush. Ediciones B. España. 
- Lewis, Norman. (1966), La virtuosa compañía: la mafia. Ed. Seix Barral. Barcelona.

- López, Obrador Andrés Manuel. (2010), La mafia que se adueño de México...y el 2012. Ed. Random House Mondadori.

- Lugo, C. Danilo. (3/VI/2005), Auditoría Criminal. En [htt://www.interamericanusa.com//].

- Mendoza, Enrique y Adela Navarro. (2011). Ya son 50 mil los muertos en la guerra antinarco: ZETA. Revista PROCESO № 1811. México.

- $\quad$ Nisbet, Robert. (1995), Conservadurismo. Alianza Editorial. España.

- $\quad$ Odalric De Caixal, i Mata, David. (2009), Historia de los conflictos asimétricos. Centro de formación interactivo para la cultura de la defensa. Universidad a distancia de Madrid.

- $\quad$ Pantaleone, Michele. (1972), Mafia y Política, Ed. Redonde, Barcelona.

- $\quad$ Pareto, Vilfredo. (1979), The Rise and The Fall of the Elites. New York.

- Reuter, Peter. (1995), The Public Interest. №. 120."The Decline of the American Mafia". Washington, D.C. EUA.

- $\quad$ Silica, Rod. (1974), La verídica historia de la mafia. Editores Asociados. México.

- Sutherland, Edwin H. (2001), "La delincuencia de las grandes empresas", en Nómadas № 1. Revista Crítica de Ciencias Sociales y Jurídicas. Madrid. UCM. en [http://www.ucm.es/ info/nomadas/1/sutherland2.htm].

- Unger, Craig. (2004), Los Bush y los Saud. "La relación secreta entre las dos dinastías más poderosas del mundo". Ed. Planeta. España.

- Wright, Mills, Charles. (1993), La Elite del Poder. Fondo de Cultura Económica. México.

- Zambrano, Pasquel Antonio. (2011), El delito de cuello blanco. www.alfonsozambrano.com/ doctrina_penal.

- Zúñiga, Rodríguez Laura. (2002), El derecho penal ante la globalización. "Redes internacionales y criminalidad: A propósito del modelo de participación en organización criminal." Madrid, España. 